\title{
$1 \quad$ Long-distance benefits of marine reserves: myth or reality?
}

2 Stéphanie Manel $^{1}$, Nicolas Loiseau ${ }^{2}$, Marco Andrello ${ }^{3}$, Katharina Fietz ${ }^{4}$, Raquel Goñi ${ }^{5}$, Aitor

3 Forcada $^{6}$, Philippe Lenfant ${ }^{7}$, Stuart Kininmonth ${ }^{8,9}$, Concepción Marcos $^{10}$, Virginie Marques ${ }^{2}$,

4 Sandra Mallol ${ }^{5}$, Angel Pérez-Rufaza ${ }^{10}$, Corinna Breusing $^{4}$, Oscar Puebla $^{4}$, David Mouillot ${ }^{2,11}$

6 1-EPHE, PSL Research University, CEFE UMR 5175, CNRS, Université de Montpellier,

7 Université Paul-Valéry Montpellier, Biogéographie et Ecologie des Vertébrés, 1919 route de

8 Mende, Montpellier 34293, France

9 2-UMR 9190 MARBEC, IRD-CNRS-IFREMER-UM, Université de Montpellier, Montpellier 1034095 France

11 3- Department of Ecology and Evolutionary Biology, University of Toronto, Toronto,

12 Ontario, Canada

13 4- GEOMAR Helmholtz Centre for Ocean Research Kiel, Evolutionary Ecology of Marine 14 Fishes, Düsternbrooker Weg 20, 24105 Kiel, Germany.

15 5- Instituto Español de Oceanografía, Centro Oceanográfico de Baleares, Moll de Ponent s/n, 1607015 Palma de Mallorca, Spain

17 6- Department of Marine Sciences and Applied Biology, University of Alicante, P.O. Box 99, 1803080 - Alicante, Spain

19 7- Univ. Perpignan Via Domitia, Centre de Formation et de Recherche sur les

20 Environnements Méditerranéens, UMR 5110, 58 Avenue Paul Alduy, F-66860 Perpignan, 21 France

22 8- School of Marine Studies, University of South Pacific, Suva, Fiji

23 9- Stockholm Resilience Centre, Stockholm University, Stockholm, Sweden

24 10- Departmento de Ecología e Hidrología, Facultad de Biología, Campus de Espinardo,

25 Regional Campus of International Excellence "Campus Mare Nostrum”, University of

26 Murcia, 30100 Murcia, Spain

27 11-Australian Research Council Centre of Excellence for Coral Reef Studies, James Cook

28 University, Townsville, QLD 4811 Australia.

29 Correspondence: stephanie.manel@ephe.psl.eu (S. Manel) 
31 Keywords: connectivity, global network, long-distance dispersal, marine reserves, marine 32 protected areas.

34 Abstract

36 Long-distance $(>40 \mathrm{~km})$ dispersal from marine reserves is poorly documented. Yet, it can 37 provide essential benefits such as seedling fished areas or connecting marine reserves into 38 networks. From a meta-analysis, we suggest that the spatial scale of marine connectivity is 39 underestimated due to the limited geographic extent of sampling designs. We also found that 40 the largest marine reserves $\left(>1,000 \mathrm{~km}^{2}\right)$ are the most isolated. These findings have important implications for the assessment of evolutionary, ecological and socio-economic long-distance

42 benefits of marine reserves. We conclude that existing methods to infer dispersal should consider the up-to-date genomic advances and also expand the spatial scale of sampling

44 designs. Incorporating long-distance connectivity in conservation planning will contribute to 45 increase the benefits of marine reserve networks. 
Benefits from marine reserves: where are we?

Marine resources are declining at an alarming rate [1,2], with more than half of the oceanic area exploited by industrial fishing [3]. In response, marine protected areas (MPAs) have been established in an effort to conserve biodiversity and sustain fisheries [4-7]. Yet, only $3.7 \%$ of the ocean is presently covered by MPAs and less than $2 \%$ by no-take MPAs (referred to as marine reserves [8]) specifically (mpatlas.org; [9]). Despite the recent establishment of largescale MPAs $\left(>100,000 \mathrm{~km}^{2}\right)$ [10], the current trend of protection is not keeping pace with the increasing human footprint on marine resources [11, 12]. In particular, the Aichi Biodiversity Target 11 established by the Convention of Biological Diversity to protect at least $10 \%$ of the ocean by 2020 is unlikely to be achieved $[9,13,14]$. In consideration of the ever-growing human population, fishing technological developments and per capita consumption rates, a new target of $30 \%$ protected area by 2030 was proposed at the 2016 International Union for

71 Conservation Nature (IUCN) World Conservation Congress in line with scientific advice [6, 15]. There is thus an urgent need to better understand the full range of benefits provided by marine reserves to optimize future conservation efforts. Theoretical and empirical studies support the positive effects of marine reserves within their boundaries and in their vicinity [16-19]. Indeed, marine reserves unambiguously host more and larger - and thus more fertile - individuals than fished areas (e.g. $[5,20,21])$. They also contribute to preserve genetic diversity [22], increase human wellbeing [23], alleviate poverty

79 [24] and facilitate adaptation to climate change [25]. In addition, when properly designed and enforced, they have the potential to increase catches of commercial species in surrounding 
81 fishing grounds [26, 27] due to juvenile or adult spillover (see glossary) [28, 29]. However,

82 such direct benefits have been typically documented at short distances from reserve 83 boundaries, i.e. from a few hundred meters to less than $40 \mathrm{~km}[16,30,31]$. In contrast, little

84 is known about the benefits of marine reserves in areas that are 40 to hundreds of kilometers 85 away from their boundaries [32].

86

87 The concept of long-distance $(>40 \mathrm{~km})$ dispersal is not new in marine ecology and the oceans 88 have been assumed to function as mostly open, well-connected systems until the last two 89 decades [33, 34], when evidence of local recruitment started to accumulate $[35,36]$. However, 90 the large-scale impacts of marine reserves resulting from long-distance dispersal of larvae 91 [37], juveniles and adults [38] are still poorly documented. The potential for long-distance 92 dispersal is highest for pelagic species, which is consistent with their widespread geographic 93 distributions [39]. Yet, recent findings based on telemetry and genetic tools indicate that 94 benthic and demersal species (hereafter called benthos), including those in the deep sea, can 95 also disperse up to hundreds of kilometers [32, 40-42]. This recognition of high dispersal 96 capabilities calls for more studies on the effect of dispersal far from reserves and for a better integration of long-distance dispersal in the design of reserve networks.

99 Here we review the potential long-distance benefits of marine reserves, including those 100 provided by relatively rare long-distance dispersal events. We focus on the benthos since their 101 adult stages can be more easily assigned to protected versus non-protected areas compared to 102 pelagic species which have large home ranges, often larger than most MPAs [43]. First, 103 through an extensive literature screening, we characterize the spatial scale of dispersal for the 104 benthos. We then discuss how existing methods can be enhanced to expand the scale of 105 connectivity analyses. Finally, we discuss the potential long-distance benefits of marine 
107 those benefits.

Spatial scale of dispersal and connectivity in the marine realm: do we capture the full picture?

112 We define marine connectivity as the exchange of individuals among marine populations

113 [44]. This exchange can take place through dispersal of individuals as larvae, juveniles, or 114 adults. When individuals reproduce successfully thereafter, demographic connectivity

115 translates into genetic connectivity. Determining the spatial scale of marine connectivity is 116 crucial for our understanding of the population dynamics, genetic structure and biogeography

117 of marine organisms, and accordingly for the design of marine reserves.

119 To obtain a global estimate of the spatial scale of marine connectivity for the benthos, we 120 conducted an extensive - but non-exhaustive - literature review over the last decade in the ISI

121 Web of Science (supplementary text S1, supplementary file S1). Of the 460 papers identified, 130 were included in our meta-analysis as they contain information about maximum sampling geographic range and maximum inferred demographic or genetic connectivity for a total of 243 species.

The different methods used to estimate dispersal distance apply to different spatial and 127 temporal scales (Table I of Box 1). The median potential dispersal distance averaged across 128 all studies based on biophysical models $(226 \mathrm{~km}$, interquartile range $=160-415 \mathrm{~km}$, number

129 of species $=56$ ) was at least four times higher than the demographic (realized and effective) 130 median dispersal distance $(42 \mathrm{~km}$, interquartile range $=27-250 \mathrm{~km}$, number of species $=55$; 
131 Figure 1A; Box 1). These results indicate that studies are either overestimating potential 132 dispersal or underestimating demographic dispersal, with some exceptions where both 133 estimates are congruent (e.g. [45]). However, assessing the full spatial extent of dispersal is 134 challenging due to the inherent difficulty of tracking or recapturing organisms over long 135 distances. With a few exceptions (e.g. [32, 41, 46]), most empirical studies of demographic 136 connectivity were conducted at scales smaller than $40 \mathrm{~km}$ [47]. Estimating demographic

137 connectivity at larger spatial scales and over multiple generations would require sampling 138 significantly more individuals and in more distant populations, which would entail high, 139 possibly prohibitive, costs. Genetic assignment approaches at the population level might be 140 scaled-up more easily than mark-recapture or parentage analysis methods and constitute a 141 promising approach when populations are genetically differentiated [48, 49]. For example,

142 putative first-generation migrants between two populations separated by $400 \mathrm{~km}$ were 143 detected in the Omani Clownfish (Amphiprion omanensis) using assignment tests [40]. If

144 populations are locally adapted, the use of genetic markers that are under divergent selection 145 can contribute to increase the power of such approaches, and can even be used in the absence 146 of neutral genetic structure [50]. Genetic isolation by distance at the population or individual 147 level [51] provides dispersal estimates that are consistent with demographic dispersal 148 estimates obtained from parentage analysis (Box 1) [52]. When a reference genome and 149 haplotype data are available, the consideration of admixture tracts [53] and blocks of 150 identity by descent [54] constitutes another promising avenue to detect recent dispersal 151 events, that can also apply in isolation by distance contexts [55].

153 Our literature review also reveals that genetic connectivity, based on Wright's Fixation Index $154\left(\mathrm{~F}_{S T}\right)$, tends to provide higher estimates than any other method (Figure 1A: median $=910 \mathrm{~km}$, 155 interquartile range $=315-2346 \mathrm{~km}$, number of species $=126)$. Yet, genetic connectivity 
156 differs from demographic connectivity as it integrates the effects, not just off migration, but

157 also genetic drift, mutation and selection. Translating genetic connectivity into demographic

158 estimates of dispersal is not straightforward [56]. This notably implies estimating effective

159 population sizes [57] or assuming specific population genetic models that are often unrealistic

160 in real-world situations [58]. Furthermore, gene flow over large geographic distances might

161 result from stepping-stone dispersal over multiple generations without necessarily implying

162 direct long-distance dispersal events [59].

163

164 Globally, the data show a universal positive correlation between the geographic sampling

165 scale of the study and the maximum dispersal or connectivity averaged across all studies and 166 organisms $(\mathrm{R}=0.7, \mathrm{p}<0.001$; Figure $1 \mathrm{~B})$. The relation holds true when analyzing the data per

167 type of dispersal estimate (potential vs. demographic vs. genetic). In $45 \%$ of the studies, the 168 dispersal distance was equal to the maximum geographic extent of the sampling. This reached $16948 \%$ when data were restricted to coastal fishes, $41 \%$ for invertebrates and $41 \%$ for deep sea 170 organisms (Figure 1C). These results suggest that estimates are limited by the spatial scale of 171 the sampling, resulting in a global underestimation of the extent of demographic and genetic 172 connectivity.

174 For genetic connectivity, an absence of population structure can also result from a lack of 175 statistical power to detect subtle population genetic structure when a small number of genetic 176 markers are used. With the advent of next-generation sequencing technologies, this 177 limitation can now be overcome by typing hundreds to millions of single nucleotide 178 polymorphism markers $[60,61]$.

179 
180 A variety of mechanisms can contribute to long-distance dispersal in marine ecosystems

181 (Figure 2). Foremost, the hydrodynamic forces at play in the marine environment are

182 expected to have a strong influence on the dispersal of pelagic larvae [62]. In addition, the

183 conditions encountered in the pelagic environment might influence growth, survival and

184 pelagic larval duration, all of which can in turn induce extreme values in spatial and temporal

185 connectivity patterns. Active larval behavior can also play an important role for the benthos

$186[63,64]$. Extreme events, such as tsunamis [65], and oceanographic eddies and fronts [66] are

187 also important, but overlooked potential dispersal vectors over long distances. They can favor

188 the survival and establishment of individuals beyond their usual dispersal range. Furthermore,

189 marine debris of natural or anthropogenic origin can constitute effective oceanic rafts for

190 dispersal [67, 68]. These debris provide refuges for larvae and adults of sessile species,

191 allowing the movement and potential establishment of a variety of species over large

192 distances. For instance, mussels from Japan arrived on the west coast of the US after nearly

193 six years at sea on debris produced by the 2011 East Japan earthquake [65]. Ice blocks also

194 allow invertebrates to disperse across distances of about $20 \mathrm{~km}$ per day [69]. Anthropogenic

195 vectors such as international vessel traffic, restocking from aquaculture [70], and species

196 translocation (Box 2) also have the potential to modify the natural spatial and temporal

197 patterns of marine connectivity [71]. Overall, the occurrence of long-distance dispersal

198 events, even if rare, suggest that marine reserves can have an effect far beyond their

199 boundaries, which calls for a re-evaluation of the spatial extent of their potential benefits.

\section{Long-distance benefits of marine reserves}

202 We consider a long-distance benefit of marine reserve any change in biomass, biological

203 processes (e.g. recruitment) or biodiversity (including genetic diversity as raw material for

204 adaptation) at distance greater than $40 \mathrm{~km}$ from reserve boundaries that contributes to 
improve ecosystem function or human livelihoods (e.g. fisheries, tourism, culture) (Figure 2).

206 Long-distance benefits from reserves can occur at different spatial and temporal scales

207 depending on the vector of dispersal (Box 1, Figure 2), and this includes both direct and stepping-stone dispersal processes.

210 Parentage analyses have demonstrated dispersal from marine reserves at more than $40 \mathrm{~km}[32$,

211 46]. For example, Almany et al. [46] revealed connectivity patterns with direct exchanges of

212 larvae over up to $150 \mathrm{~km}$ among reefs with varying levels of protection. Larval dispersal

213 from reserves towards exploited areas located at more than $100 \mathrm{~km}$ has also been suggested

214 by biophysical models [37, 72]. Yet, empirical studies showing an effect of marine reserves

215 on fished areas are largely restricted to spatial scales smaller than $40 \mathrm{~km}$ (e.g. [26, 73, 74]).

216 Scaling-up these studies is challenging for a variety of logistic reasons, including the

217 difficulty to sample and monitor individuals over large spatial scales.

219 Even if long-distance dispersal events from marine reserves are rare, a few successful

220 migrants can be sufficient to re-colonize areas where local populations have been extirpated

221 or to expand species distributions in response to global change [75]. Long-distance dispersal

222 between populations that are genetically differentiated or locally adapted can moreover

223 contribute to limit inbreeding, increase genetic diversity and facilitate adaptation to a

224 changing environment [25, 76]. However, in case of local adaptation, long-distance dispersal

225 can also reduce fitness of recipient populations through immigration of locally maladapted

226 alleles [77].

227

228 Active translocations from marine reserves can also contribute to restore locally depleted or 229 extinct populations [78]. For example, the Bumphead Parrotfish (Bolbometopon muricatum) 
230 is highly targeted by spear fishers due to its large size and therefore population densities tend

231 to be low in areas close to human populations [79]. This species is only abundant in reserves

232 and on the most protected reefs such as in Palau where it aggregates to spawn. These

233 populations have been used as a source of eggs and larvae for active translocations (Box 2).

234 Nearly 500 translocation projects of 242 marine species have been recorded [78]. However,

235 still few projects take advantage of large stocks in marine reserves. It should also be

236 emphasized that translocations entail a number of risks (e.g. disease, invasion, gene pool

237 mixing). Overall, marine reserves could support a wide variety of long-distance benefits that

238 are potentially underestimated and that should be considered for the design of reserve 239 networks.

240

241 Implications of long-distance dispersal for marine reserve design

242 An underestimate of dispersal ability can profoundly influence the design of marine reserve

243 networks. Long-distance dispersal can potentially connect distant and isolated reserves, and 244 sustain biodiversity and biomass in exploited areas located at more than $40 \mathrm{~km}$ from their 245 boundaries. In this respect, long-distance dispersal provides a fresh perspective on two long246 lasting and active debates in the marine reserve literature.

248 First, long-distance dispersal has implications for the unresolved single-large-or-several249 small (SLOSS) marine reserve debate. Simulations suggest that a network of well-connected 250 reserves on a scale of $10-100 \mathrm{~km}$ can meet both conservation and fisheries goals [7, 80].

251 However, the idea that a network constituted of many small reserves spaced within species 252 maximum dispersal distance [4] maximizes reserve benefits to fisheries has been recently 253 revisited and challenged. Based on a spatially explicit model of population dynamics, De Leo $254 \&$ Micheli [81] show that for larval dispersal $>10 \mathrm{~km}$, one or two large reserves are more 
efficient in terms of fisheries gains than 10 or 20 small reserves covering the same area. This

256 is notably due to the fact that large $\left(>100 \mathrm{~km}^{2}\right)$, old $(>10$ years, [5]) and well-managed

257 reserves tend to increase fish density and biomass [5, 82], and that large females over-

258 contribute to reproduction since the relation between female body mass and reproductive 259 output is hyperallometric for the vast majority of fishes (i.e. a 2-kg female has a higher 260 reproductive output in terms of egg number, volume and energy, than two 1-kg females [83]).

261 We can therefore expect large, old and well-managed reserves to disproportionately

262 contribute to larval seedling within a network when dispersal distances are greater than ten

263 kilometers. Using a rigorously calibrated metapopulation model with empirical data from the

264 Great Barrier Reef, Hopf et al. [84] also show that reserves are unable to compensate for the 265 increased mortality outside reserve boundaries when they are small or at the periphery of the 266 metapopulation [84]. In contrast, the establishment of a single large reserve, that is able to 267 seed overexploited areas through dispersal, is expected to result in higher population growth 268 within reserve boundaries and shorter recovery times after overexploitation outside the 269 reserve. Finally, a global analysis indicates that when larval dispersal distances are long (>40 $270 \mathrm{~km}$ ), the magnitude of biomass increase within large reserves is expected to be sufficient to 271 compensate for the redistributed fishing pressure associated with reserve establishment [85].

272

273 The median nearest-neighbor distance between marine reserves is estimated at $12 \mathrm{~km}$ globally 274 (interquartile distance: 4 to $40 \mathrm{~km}$ ) (Supplementary text S2). This geographical pattern is 275 highly variable, with some reserves being very isolated (e.g. the Parque Natural Obô do 276 Príncipe in São Tomé and Príncipe at $4130 \mathrm{~km}$ from the nearest reserve, the Monumento 277 Natural do Arquipelago de Sao Pedro e Sao Paulo at $940 \mathrm{~km}$ off the coast of Brazil) (Figure 2783 A, supplementary text S2). Fortunately, $76 \%$ of reserves are found closer to the nearest 279 reserve than the median demographic dispersal distance estimated in our literature review (42 
$\mathrm{km}$ ) (Figure 3B). It implies that three-quarters of marine reserves are potentially

281 demographically embedded in a connected network providing spatial insurance. The median

282 nearest-neighbor distance in the $24 \%$ remaining reserves is estimated to be $129 \mathrm{~km}$, with a

283 very skewed distribution (Figure 3B). Notably, $83 \%$ of large reserves $\left(>1000 \mathrm{~km}^{2}\right)$ are

284 isolated $(>42 \mathrm{~km}$ ) (Figure 3C). The mean nearest neighbor of this subset of large marine

285 reserves is $359 \mathrm{~km}$ away, decreasing their potential contribution to the global network.

286 Therefore, the largest marine reserves, allowing large spillover of individuals and providing

287 benefits for both biodiversity and human population, are the least connected. However, we did

288 not consider how sea surface currents could modify our assessment of connectivity among

289 isolated reserves.

290

291 Second, long-distance dispersal has also implications for prioritizing the conservation of

292 human-impacted versus non-impacted areas. Intuitively, one can see little benefit in placing

293 reserves in isolated areas which are difficult to access and therefore de facto protected [86].

294 On the other hand, reserves close to dense human populations can mitigate but not eliminate

295 the high anthropogenic pressure outside but also inside their boundaries [87]. It has therefore

296 been suggested that reserves located at an intermediate level of human pressure might offer

297 the maximum benefits in terms of fish biomass within their boundaries [87]. For top predators

298 like sharks, only isolated marine reserves with low human pressure can be effective [87]. The

299 realization of long-distance dispersal would also make a case for the protection of such areas

300 isolated from human pressure. More generally, it would suggest to reconsider the design of

301 marine reserve networks with fewer but larger reserves, including isolated ones, to sustain

302 large populations of large individuals, even of top predators, that can massively seed larvae

303 towards fishing grounds. Tools that integrate species dispersal in conservation planning are

304 now available to reach both conservation and fisheries management objectives in a 
multispecies framework [88]. The consideration of long-distance dispersal would certainly

306 modify the outputs of conservation plans.

\section{Concluding remarks}

309 Marine dispersal has been extensively documented at short distance (mostly $<40 \mathrm{~km}$ ). We

310 suggest that this has been due, at least in part, to logistic constraints and a restricted

311 geographic extend of the sampling design (e.g. the median sampling distance in parentage

312 analyses is only $33 \mathrm{~km}$, interquartile range $=29-60 \mathrm{~km}$, number of species $=22$ ). While a

313 significant fraction of dispersal indeed occurs at small spatial scales, the fraction of the

314 dispersal kernel that we are missing is largely unknown (see Outstanding Questions). A few

315 recent empirical studies have demonstrated dispersal of fish at larger spatial scales (up to 400

$316 \mathrm{~km}$ ), but even these estimates were limited by the maximum sampling distance [40]. Dispersal

317 estimates from biophysical modelling studies at larger spatial scales suggest even longer

318 dispersal distances (median sampling distances $=600 \mathrm{~km}$, interquartile range: $237-1400$,

319 Figure 1A). Such long-distance connectivity patterns remain challenging to validate

320 empirically, but have potentially important consequences in terms of reserve design and

321 benefits. The more isolated reserves are, the more critical long-distance dispersal becomes to

322 maintain source-sink dynamics between protected and exploited populations. Thus, long-

323 distance benefits imply a more regional and network-based perspective, which entails specific

324 challenges. Long-distance dispersal will often cross countries as well in-shore-offshore

325 boundaries. The designation of marines reserves is largely carried out by individual countries

326 and they rarely able coordinate efforts with other countries and high-seas authorities [89].

327 Furthermore, the focus on marine reserves is strongly constrained by the perspective of local

328 stakeholders [15], which is perfectly justified but should nonetheless not obliterate a broader 329 perspective. 
330 We suggest scaling-up dispersal studies at regional instead of local scale. We can now

331 genotype a large number of genetic markers, which provides the opportunity to apply

332 population-level assignment tests at large spatial scales and in a context of low spatial

333 structure [90]. Such studies can be guided by high-resolution biophysical models to target the

334 specific populations among which long-distance distance dispersal occurs. A large number of

335 single nucleotide polymorphism markers will also provide the statistical power to detect very

336 subtle population structure, which will allow refining genetic connectivity estimates [90, 91].

337 Finally, approaches based on admixture tracts [53] and blocks of identity by descent [54] are

338 largely untapped. The combination of genetic, chemical and biophysical approaches within an

339 integrative statistical framework also appears to be a promising approach to estimate long-

340 distance dispersal [92] and guide the design of new reserve networks to keep pace with ever

341 increasing threats on marine ecosystems.

\section{Acknowledgments}

344 Funding and support come from the European project RESERVEBENFIT (European call 345 BIODIVERSA3 2015-2016 call) and the CNRS for the PICS SEACONNECT. We thank

346 Pierre Lopez for the illustration 2 of this paper. We thank Tom Bowling (Biota Aquaculture,

347 Palau) for the pictures used in the figure in Box 2. We thank David Diaz for helpful

348 discussions. We acknowledge the editor and the three anonymous reviewers for their

349 comments that helped clarifying several aspects of the study.

\section{References}


352 1. McCauley, D.J. et al. (2015) Marine defaunation: Animal loss in the global ocean. Science

353 DOI: $10.1126 /$ science. 1255641.

354 2. Worm, B. (2016) Averting a global fisheries disaster. Proc. Natl. Acad. Sci. U.S.A.

$355 \quad 113,4895-4897$.

356 3. Kroodsma, D.A. et al. (2018) Tracking the global footprint of fisheries. Science 359, 904-

357907.

358 4. Gaines, S.D. et al. (2010) Designing marine reserve networks for both conservation and

359 fisheries management. Proc. Natl. Acad. Sci. U.S.A. 107, 18286-18293.

360 5. Edgar, G.J. et al. (2014) Global conservation outcomes depend on marine protected areas

361 with five key features. Nature 506, 216-220.

362 6. Krueck, N.C. et al. (2017) Marine reserve targets to sustain and rebuild unregulated

363 Fisheries. Plos Biol. 15, 1-20.

364 7. Lubchenco, J. and Grorud-Colvert, K. (2015) Making waves: The science and politics of 365 ocean protection. Science 350, 382-383.

366 8. Costello, M.J. and Ballantine, B. (2015) Biodiversity conservation should focus on no-take

367 Marine Reserves. Trends Ecol. Evol. 30, 507-509.

368 9. Sala, E. et al. (2018) Assessing real progress towards effective ocean protection. Mar. 369 Policy 91, 11-13.

370 10. O’Leary, B.C. et al. (2018) Addressing criticisms of large-scale Marine Protected Areas. 371 BioSci. 68, 359-370.

372 11. Watson, R.A. et al. (2015) Marine foods sourced from farther as their use of global ocean 373 primary production increases. Nat. Commun. 6, DOI: $10.1038 /$ ncomms 8365.

374 12. Halpern, B.S. et al. (2015) Spatial and temporal changes in cumulative human impacts on 375 the world's ocean. Nat. Commun. 6, DOI: 10.1038/ncomms861.

376 13. Tittensor, D.P. et al. (2014) A mid-term analysis of progress toward international 377 biodiversity targets. Science 346, 241-244. 
378 14. Di Marco, M. et al. (2016) Global biodiversity targets require both sufficiency and 379 efficiency. Conserv. Lett. 9, 395-397.

380 15. O'Leary, B.C. et al. (2016) Effective coverage targets for ocean protection. Conserv. Lett. $3819,398-404$.

382 16. Gell, F.R. and Roberts, C.M. (2003) Benefits beyond boundaries: the fishery effects of 383 marine reserves. Trends Ecol. Evol. 18, 448-455.

384 17. Lester, S.E. et al. (2009) Biological effects within no-take marine reserves: a global 385 synthesis. Mar. Ecol. Prog. Ser. 384, 33-46.

386 18. Stobart, B. et al. (2009) Long-term and spillover effects of a marine protected area on an 387 exploited fish community. Mar. Ecol. Prog. Ser. 384, 47-60.

388 19. Sciberras, M. et al. (2015) Evaluating the relative conservation value of fully and partially 389 protected marine areas. Fish Fish. 16, 58-77.

390 20. Diaz, D. et al. (2016) A 25-year marine reserve as proxy for the unfished condition of an 391 exploited species. Biol. Conserv. 203, 97-107.

392 21. MacNeil, M.A. et al. (2015) Recovery potential of the world's coral reef fishes. Nature $393520,341-344$.

394 22. Perez-Ruzafa, A. et al. (2006) Effects of fishing protection on the genetic structure of fish 395 populations. Biol. Conserv. 129, 244-255.

396 23. Coulthard, S. et al. (2017) Exploring 'islandness' and the impacts of nature conservation 397 through the lens of wellbeing. Environ. Conserv. 44, 298-309.

398 24. Gurney, G.G. et al. (2014) Poverty and protected areas: An evaluation of a marine 399 integrated conservation and development project in Indonesia. Glob. Environ. Change 26, $400 \quad 98-107$.

401 25. Roberts, C.M. et al. (2017) Marine reserves can mitigate and promote adaptation to 402 climate change. Proc. Natl. Acad. Sci. U.S.A. 114, 6167-6175. 
403

404

405

406

407

408

409

410

411

412

413

414

415

416

417

418

419

420

421

422

423

424

425

426

26. Kerwath, S.E. et al. (2013) Marine protected area improves yield without disadvantaging fishers. Nat. Commun. 4, DOI: 10.1126/science.

27. Di Franco, A. et al. (2016) Five key attributes can increase marine protected areas performance for small-scale fisheries management. Sci. Rep. 6, DOI: 10.1038/srep38135.

28. Abesamis, R.A. and Russ, G.R. (2005) Density-dependent spillover from a marine reserve: Long-term evidence. Ecol. Appl. 15, 1798-1812.

29. Goni, R. et al. (2010) Net contribution of spillover from a marine reserve to fishery catches. Mar. Ecol. Prog. Ser. 400, 233-243.

30. Russ, G.R. and Alcala, A.C. (2011) Enhanced biodiversity beyond marine reserve boundaries: The cup spillith over. Ecol. Appl. 21, 241-250.

31. Goni, R. et al. (2006) Spillover of spiny lobsters Palinurus elephas from a marine reserve to an adjoining fishery. Mar. Ecol. Prog. Ser. 308, 207-219.

32. Williamson, D.H. et al. (2016) Large-scale, multidirectional larval connectivity among coral reef fish populations in the Great Barrier Reef Marine Park. Mol. Ecol. 25, 6039-6054.

33. Roberts, C.M. (1997) Connectivity and management of Caribbean coral reefs. Science $278,1454-1457$.

34. Mora, C. and Sale, P.F. (2002) Are populations of coral reef fish open or closed? Trends Ecol. Evol. 17, 422-428.

35. Jones, G.P. et al. (1999) Self-recruitment in a coral reef fish population. Nature 402, 802804.

36. Swearer, S.E. et al. (1999) Larval retention and recruitment in an island population of a coral-reef fish. Nature 402, 799-802.

37. Andrello, M. et al. (2017) Global mismatch between fishing dependency and larval supply from marine reserves. Nat. Commun. 8, DOI: 10.1038/ncomms16039. 
38. Christie, M.R. (2010) Parentage in natural populations: novel methods to detect parentoffspring pairs in large data sets. Molecular Ecolog Mol. Ecol. Resour. 10, 115-128.

39. Costello, M.J. et al. (2017) Marine biogeographic realms and species endemicity. Nat. Commun. 8, https://doi.org/10.1038/s41467-017-01121-2.

40. Simpson, S.D. et al. (2014) Long-distance dispersal via ocean currents connects omani clownfish populations throughout entire species range. PLoS ONE 9, DOI: 10.1371/journal.pone.0107610.

41. Christie, M.R. et al. (2010) Larval connectivity in an effective network of Marine Protected Areas. PLoS ONE 5, DOI: 10.1371/journal.pone.0015715.

42. Espinoza, M. et al. (2015) Contrasting movements and connectivity of reef-associated sharks using acoustic telemetry: implications for management. Ecol. Appl. 25, 2101-2118. 43. Daly, R. et al. (2018) Refuges and risks: Evaluating the benefits of an expanded Marine Protecte Area network for mobile apex predators. Divers. Distrib. 24, 1217-1230. 44. Cowen, R.K. et al. (2006) Scaling of connectivity in marine populations. Science 311, $522-527$

442 45. Costello, M.J. (2009) How sea lice from salmon farms may cause wild salmonid declines 443 in Europe and North America and be a threat to fishes elsewhere. Proc. Royal. Soc. Lond. B Biol. Sci. 276, 3385-3394.

46. Almany, G.R. et al. (2017) Larval fish dispersal in a coral-reef seascape. Nat. Ecol. Evol. 1, DOI: 10.1038/s41559-017-0148.

447 47. Hameed, S.O. et al. (2016) Inverse approach to estimating larval dispersal reveals limited 448 population connectivity along $700 \mathrm{~km}$ of wave-swept open coast. Proc. Royal. Soc. Lond. B 449 Biol. Sci. 283, doi: 10.1098/rspb.2016.0370.

450 48. Paetkau, D. et al. (1995) Microsatellite analysis of population-structure in Canadian polar 451 bears. Mol. Ecol. 4, 347-354. 
49. Manel, S. et al. (2005) Assignment methods: matching biological questions with appropriate techniques. Trends Ecol. Evol. 20, 136-142.

50. Gagnaire, P.-A. et al. (2015) Using neutral, selected, and hitchhiker loci to assess connectivity of marine populations in the genomic era. Evol. Appl. 8, 769-786.

51. Puebla, O. et al. (2012) On the spatial scale of dispersal in coral reef fishes. Mol. Ecol. $21,5675-5688$.

52. Pinsky, M. et al. (2017) Marine dispersal scales are congruent over evolutionary and ecological time. Curr. Biol. 27, 1-6.

460 53. Liang, M. and Nielsen, R. (2014) The lengths of admixture tracts. Genet. 197, 461 https://doi.org/10.1534/genetics.114.162362.

462 54. Browning, S.R. and Browning, B.L. (2012) Identity by descent between distant relatives: 463 detection and applications. Annu. Rev. Genet. 46, 617-633.

464 55. Ringbauer, H. et al. (2017) Inferring recent demography from isolation by distance of long 465 shared sequence blocks. Genet. 205, https://doi.org/10.1534/genetics.116.196220.

466 56. Lowe, W.H. and Allendorf, F.W. (2010) What can genetics tell us about population 467 connectivity? Mol. Ecol. 19, 3038-3051.

468 57. Beerli, P. and Felsenstein, J. (2001) Maximum likelihood estimation of a migration matrix 469 and effective population sizes in n subpopulations by using a coalescent approach. Proc. Natl. $470 \quad$ Acad. Sci. U.S.A. 98, 4563-4568.

471 58. Whitlock, M.C. and McCauley, D.E. (1999) Indirect measures of gene flow and 472 migration: $\mathrm{F}_{S T}$ not equal $1 /(4 \mathrm{Nm}+1)$. Heredity $82,117-125$.

473 59. Saura, S. et al. (2014) Stepping stones are crucial for species' long-distance dispersal and 474 range expansion through habitat networks. J. Appl. Ecol. 51, 171-182. 
60. Fischer, M.C. et al. (2017) Estimating genomic diversity and population differentiation an empirical comparison of microsatellite and SNP variation in Arabidopsis halleri. BMC Genomics 18, https://doi.org/10.1186/s12864-016-3459-7.

61. Hodel, R.G.J. et al. (2017) Adding loci improves phylogeographic resolution in red mangroves despite increased missing data: comparing microsatellites and RAD-Seq and investigating loci filtering. Sci. Rep. 7, https://doi.org/10.1038/s41598-017-16810-7.

62. Gillespie, R.G. et al. (2012) Long-distance dispersal: a framework for hypothesis testing. Trends Ecol. Evol. 27, 47-56.

63. Faillettaz, R. et al. (2018) Larval fish swimming behavior alters dispersal patterns from Marine Protected Areas in the North-Western Mediterranean Sea. Front. Mar. Sci. 5, https://doi.org/10.3389/fmars.2018.00097.

64. Nanninga, G.B. and Manica, A. (2018) Larval swimming capacities affect genetic differentiation and range size in demersal marine fishes. Mar. Ecol. Prog. Ser. 589, 1-12.

65. Carlton, J.T. et al. (2017) Tsunami-driven rafting: Transoceanic species dispersal and implications for marine biogeography. Science 357, 1402.

66. Shulzitski, K. et al. (2016) Encounter with mesoscale eddies enhances survival to settlement in larval coral reef fishes. Proc. Natl. Acad. Sci. U.S.A. 113, 6928-6933.

67. Mora, C. et al. (2001) Dispersal of juvenile and adult reef fishes associated with floating objects and their recruitment into Gorgona Island Reefs, Colombia. Bull. Mar. Sci. 68, 557561.

68. Castro, J.J. et al. (2001) A general theory on fish aggregation to floating objects: An alternative to the meeting point hypothesis. Rev. Fish Biol. Fish. 11, 255-277.

69. Macfarlane, C.B.A. et al. (2013) Dispersal of marine benthic invertebrates through ice rafting. Ecol. 94, 250-256. 
70. Waters, C.G. et al. (2013) A methodology for recruiting a giant clam, Tridacna maxima,

500 directly to natural substrata: A first step in reversing functional extinctions? Biol.Cons. 160,

$501 \quad 19-24$.

502 71. Clarke Murray, C. et al. (2011) Recreational boating: a large unregulated vector 503 transporting marine invasive species. Divers. Distrib. 17, 1161-1172.

504 72. Andrello, M. et al. (2013) Low Connectivity between Mediterranean Marine Protected

505 Areas: A biophysical modeling approach for the Dusky Grouper Epinephelus marginatus.

506 PLoS ONE 8, DOI: 10.1371/journal.pone.0068564.

507 73. Harrison, H.B. et al. (2012) Larval export from marine reserves and the recruitment

508 benefit for fish and fisheries. Curr. Biol. 22, 1023-1028.

509 74. Le Port, A. et al. (2017) Temperate marine protected area provides recruitment subsidies

510 to local fisheries. Proc. Royal. Soc. Lond. B Biol. Sci. 284, DOI: 10.1098/rspb.2017.1300.

511 75. Stuart-Smith, R.D. et al. (2015) Thermal biases and vulnerability to warming in the

512 world's marine fauna. Nature 528, 88-92.

513 76. Kremer, A. et al. (2012) Long-distance gene flow and adaptation of forest trees to rapid

514 climate change. Ecol. Lett. 15, 378-392.

515 77. Bolnick, D.I. and Nosil, P. (2007) Natural selectin in populations subject to a migration 516 load. Evol. 61, 2229-2243.

517 78. Swan, K.D. et al. (2016) Managing marine biodiversity: The rising diversity and 518 prevalence of marine conservation translocations. Conserv. Lett. 9, 239-251.

519 79. Bellwood, D.R. et al. (2012) Human activity selectively impacts the ecosystem roles of 520 parrotfishes on coral reefs. Proc. Natl. Acad. Sci. U.S.A 279, DOI: 10.1098/rspb.2011.1906.

521 80. Pelc, R.A. et al. (2010) Detecting larval export from marine reserves. Proc. Natl. Acad. 522 Sci. U.S.A. 107, 18266-18271. 
523 81. De Leo, G.A. and Micheli, F. (2015) The good, the bad and the ugly of marine reserves

524 for fishery yields. Philos. Trans. R. Soc. B Biol. Sci. 370, DOI: 10.1098/rstb.2014.0276.

525 82. Claudet, J. et al. (2008) Marine reserves: size and age do matter. Ecol. Lett. 11, 481-489.

526 83. Barneche, D.R. et al. (2018) Fish reproductive-energy output increases disproportionately

527 with body size. Science 360, 642-644.

528 84. Hopf, J.K. et al. (2016) Fishery consequences of marine reserves: short-term pain for 529 longer-term gain. Ecol. Appl. 26, 818-829.

530 85. Halpern, B.S. et al. (2010) Placing marine protected areas onto the ecosystem-based 531 management seascape. Proc. Natl. Acad. Sci. U.S.A. 107, 18312-18317.

532 86. Devillers, R. et al. (2014) Reinventing residual reserves in the sea: are we favouring ease 533 of establishment over need for protection? Aquat. Conserv.: Mar. Freshwat. Ecosyst. 25, $534 \quad 480-504$.

535 87. Cinner, J.E. et al. (2018) Gravity of human impacts mediates coral reef conservation 536 gains. Proc. Natl. Acad. Sci. U.S.A. 115, DOI: 10.1073/pnas.1708001115.

537 88. Magris, R.A. et al. Biologically representative and well-connected marine reserves 538 enhance biodiversity persistence in conservation planning. Cons. Lett. 11 539 https://doi.org/10.1111/conl.12439.

540 89. Treml, E.A. et al. (2015) Analyzing the (mis)fit between the institutional and ecological 541 networks of the Indo-West Pacific. Glob. Environ. Change 31, 263-271.

542 90. Benestan, L. et al. (2015) RAD genotyping reveals fine-scale genetic structuring and 543 provides powerful population assignment in a widely distributed marine species, the 544 American lobster (Homarus americanus). Mol. Ecol. 24, 3299-3315.

545 91. Nielsen, E.E. et al. (2012) Gene-associated markers provide tools for tackling illegal 546 fishing and false eco-certification. Nat. Commun. 3, DOI: 10.1038/ncomms1845. 
92. Gaggiotti, O.E. (2017) Metapopulations of marine species with larval dispersal: A

548 counterpoint to Ilkka's Glanville fritillary metapopulations. Ann. Zool. Fennici 54, 97-112.

549 93. Bryan-Brown, D.N. et al. (2017) Patterns and trends in marine population connectivity 550 research. Mar. Ecol. Prog. Ser. 585, 243-256.

551 94. Kool, J.T. et al. (2013) Population connectivity: recent advances and new perspectives.

$552 \quad$ Lands. Ecol. 28, 165-185.

553 95. Calò, A. et al. (2013) A review of methods to assess connectivity and dispersal between

554 fish populations in the Mediterranean Sea. Adv. Oceano. Limn. 4, 150-175.

555 96. Gallego, A. et al. (2017) Bio-physical connectivity patterns of benthic marine species used 556 in the designation of Scottish nature conservation marine protected areas. Ices J. Mar. Sci. 74, $557 \quad 1797-1811$.

558 97. Treml, E.A. et al. (2008) Modeling population connectivity by ocean currents, a graph559 theoretic approach for marine conservation. Lands. Ecol. 23, 19-36.

560 98. Treml, E.A. et al. (2015) Identifying the key biophysical drivers, connectivity outcomes, 561 and metapopulation consequences of larval dispersal in the sea. Mov. Ecol. 3, DOI: 562 10.1186/s40462-015-0045-6.

563 99. Planes, S. et al. (2009) Larval dispersal connects fish populations in a network of marine 564 protected areas. Proc. Natl. Acad. Sci. U.S.A. 106, 5693-5697.

565 100. Saenz-Agudelo, P. et al. (2011) Connectivity dominates larval replenishment in a coastal 566 reef fish metapopulation. Proc. Royal. Soc. Lond. B Biol. Sci. 278, 2954-2961.

567 101. Gandra, M. et al. (2018) Diel and seasonal changes in the spatial behaviour of a soft568 sediment fish (Solea senegalensis) inside a marine reserve. Mar. Environ. Res. 135, 82-92.

569 102. Starrs, D. et al. (2016) All in the ears: unlocking the early life history biology and spatial 570 ecology of fishes. Biol. Rev. 91, 86-105. 
571 103. Calò, A. et al. (2013) A review of methods to assess connectivity and dispersal between

572 fish populations in the Mediterranean Sea. Adv. Oceano. Limn. 4, 150 - 175.

573 104. Jones, G. (2015) Mission impossible: Unlocking the secrets of coral reef fish dispersal.

574 In Ecology of Fishes on Coral Reefs. (Mora, C) Cambridge University Press, pp. 16-27.

575 Cambridge, UK,.

576 105. Rousset, F. (2000) Genetic differentiation between individuals. J. Evol. Biol. 13, 58-62.

577 106. Leblois, R. et al. (2004) Influence of spatial and temporal heterogeneities on the 578 estimation of demographic parameters in a continuous population using individual 579 microsatellite data. Genet. 166, 1081-1092.

580 107. Gutenkunst, R.N. et al. (2009) Inferring the joint demographic history of multiple 581 populations from multidimensional SNP frequency data. PLoS Genet. 5, 582 https://doi.org/10.1371/journal.pgen.1000695.

\section{Figure Legends}

\section{Figure 1: The spatial scale of sampling constraints dispersal estimates}

587 (A) Boxplot representing the maximum dispersal distance and the sampling geographic extent

588 across all studies. Central lines represent median values and whiskers first and third quartiles.

589 (B) Mean maximum dispersal distance increases with the maximal sampling geographic

590 extent and (C) the pattern remains consistent among groups: fish, invertebrates and deep-sea 591 organisms (>200 m). In (B) and (C), the color gradient displays the difference between 592 maximal dispersal estimate and sampling geographic extent, with warmer colors (red) 593 indicating that the maximum dispersal distance is closer to the maximal sampling geographic 594 extent. The methods used to estimate connectivity include tracking, parentage analysis, 595 assignment tests and isolation by distance (= demographic dispersal) described in Box 1 (see 
596 B and C), biophysical models (potential dispersal), and genetic connectivity estimated from

597 Fixation Index $\left(\mathrm{F}_{S T}\right)$. See supplementary method S1 and supplementary file S1 for details on 598 the data used to generate the figure.

Figure 2: Potential long-distance dispersal processes and marine reserve benefits from

601 The main processes that contribute to long-dispersal distance are indicated with numbers and

602 the main benefits due to long-dispersal distance are indicated with letters. The marine reserve

603 is represented by a circle. (1) Active dispersal can drive larvae or adults far from the reserve 604 boundaries, independently of the sea currents. (2) Larvae are pelagic and disperse passively

605 due to currents. (3) They can associate with floating and drifting debris. (4) Translocation

606 involves deliberately moving organisms from one site ("productive" reserves) to another (e.g.

607 overexploited population). Thus, long distance dispersal can (A) increase biomass in fished

608 areas far from the reserve, (B) potentially maintain species and genetic diversity across

609 reserves, (C) maintain commercially and culturally important species that were the target of 610 protection in the reserve.

612 Figure 3: Connectivity patterns in the global network of marine reserves.

613 (A) Map showing the neighbor distance for each marine reserve, i.e. the distance to the 614 nearest marine reserves. To improve the visibility of the figure, we used both size and color of 615 the circles to indicate the nearest-neighbor distance of each marine reserve. Small yellow 616 circles indicate the most connected marine reserves (e.g. Scandinavian region or Australia) 617 while large blue circles indicate the most isolated reserves (e.g. Western African coast). (B) 618 Distribution of nearest-neighbor distances between marine reserves. The median and mean 619 nearest-neighbor distances are $12 \mathrm{~km}$ and $65 \mathrm{~km}$, respectively. The dashed red line indicates 
620 the demographic median dispersal distance estimated for all organisms from the meta-analysis

$621(42 \mathrm{~km}) .(\mathrm{C})$ The nearest-neighbor distance increases with the no-take surface area of marine 622 reserves (from 752 no-take marine reserves). 


\section{Box}

624 Box 1: Methods for estimating long-distance dispersal in marine ecosystems

625 Methods to estimate marine dispersal [93-95] can be partitioned into three categories:

626 A. Potential dispersal (inferred from biophysical models)

627 Biophysical models can be used to simulate larval dispersal trajectories over large spatial and 628 temporal scales (Table I) [96]. These models usually incorporate three elements: a physical 629 model that simulates the ocean hydrodynamics, a particle tracking model that simulates the 630 passive movement of virtual larvae, and optionally a coupled model that simulates the activity 631 of the larvae when information on their ecology, behavior and physiology is available [97]. 632 This third element is often lacking and it is therefore important to better understand the 633 biology of marine larvae. Biophysical models are becoming increasingly complex and 634 realistic, yet they always need to be validated with empirical data [98].

636 B. Realized dispersal (dispersal took place, but dispersers can or cannot successfully 637 reproduce)

638 Specific dispersal events can be inferred using genetics. Parentage analyses identify dispersal 639 events by using individual genotypes to assign juveniles to their parents [99]. This approach 640 provides a snapshot of dispersal events over one generation. It requires considerable effort to 641 sample and genotype a large number of juveniles and potential parents. Similarly, population 642 genetic assignment tests use individual genotypes to assign individuals to their population of 643 origin [48]. This approach relies on the occurrence of genetic structure among populations 644 [100], but can also be applied in the absence of population genetic structure if populations are 645 locally adapted [50]. Various tracking methods can also identify dispersal events. Acoustic 646 telemetry can be used to observe the movement of individuals, often adults, providing the 647 opportunity to directly observe dispersal [101]. Electronic and physical tags can provide 
648 information on the movement of individuals. Some, however, have the drawback that

649 individuals need to be recaptured to retrieve the data. Otolith analyses can also provide 650 evidence of dispersal when the microchemistry or stable isotope composition of populations 651 differ $[102,103]$. When these approaches are applied to many individuals, it is possible to 652 derive empirical distributions of dispersal kernel [104]. Yet the fact that individuals disperse 653 does not necessary imply that they will successfully reproduce.

654

C. Effective dispersal (dispersal took place and dispersers successfully reproduced)

In the presence of genetic isolation by distance [105], it is possible to estimate dispersal at ecological timescales (tens of generations, [106]). This approach can be applied at the individual or population level. Another interesting avenue to infer dispersal is cline analysis [50]. Additional approaches based on coalescent theory [57] or the site frequency spectrum

661 [107] go deeper back in time (tens to thousands of generations) and are therefore less relevant 662 at ecological timescales.

663

664 Table I: Spatial extent and temporal resolution of the various methods used to estimate 665 individual dispersal and connectivity in marine organisms.

\begin{tabular}{|l|l|l|l|l|l|l|}
\hline & \multicolumn{3}{|l|}{$\begin{array}{l}\text { Spatial } \\
\text { extent }\end{array}$} & $\begin{array}{l}\text { Temporal } \\
\text { resolution }\end{array}$ \\
\hline $\begin{array}{l}\text { Dispersal } \\
\text { category }\end{array}$ & Method & $\begin{array}{l}\text { Low } \\
(1-40 \\
\mathrm{km})\end{array}$ & $\begin{array}{l}\text { Medium } \\
(40-100 \\
\mathrm{km})\end{array}$ & $\begin{array}{l}\text { Large } \\
(=>100 \\
\mathrm{km})\end{array}$ & $\begin{array}{l}\text { Within } \\
\text { generation }\end{array}$ & $\begin{array}{l}\text { trans- } \\
\text { generation } \\
\text { al }\end{array}$ \\
\hline Potential & Biophysical & & $\mathrm{x}$ & $\mathrm{x}$ & $\mathrm{x}$ & \\
\hline Realized & Parentage & $\mathrm{x}$ & $\mathrm{x}$ & $\mathrm{x}$ & & $\mathrm{x}$ \\
\cline { 2 - 8 } & Assignment & $\mathrm{x}$ & $\mathrm{x}$ & $\mathrm{x}$ & $\mathrm{x}$ & $\mathrm{x}$ \\
\cline { 2 - 8 } & Tracking & $\mathrm{x}$ & $\mathrm{x}$ & $\mathrm{x}$ & $\mathrm{x}$ & $\mathrm{x}$ \\
\cline { 2 - 8 } & Otolith & $\mathrm{x}$ & $\mathrm{x}$ & $\mathrm{x}$ & $\mathrm{x}$ & $\mathrm{x}$ \\
\hline Effective & $\begin{array}{l}\text { Isolation by } \\
\text { distance }\end{array}$ & $\mathrm{x}$ & $\mathrm{x}$ & & & $\mathrm{x}$ \\
\hline & $\begin{array}{l}\text { Cline } \\
\text { analysis }\end{array}$ & $\mathrm{x}$ & $\mathrm{x}$ & $\mathrm{x}$ & & \\
\hline
\end{tabular}




\section{Box 2}

670 Translocation is the process by which living organisms are deliberately removed from one site 671 for release in another. This definition excludes captive or cultivated organisms, sometimes 672 genetically modified, that are massively released into the wild to support agriculture, 673 fisheries, aquarium trade or pest control. The translocation process begins with the capture of 674 wild organisms in a donor site and ends with post-release monitoring in the receiving site. 675 Translocation has only recently become prominent in the oceans, particularly in coastal 676 environments, where human impacts are the highest [67]. Translocations are equivalent to 677 long-dispersal events.

678

679 Translocation in terrestrial environments is historically more common from non-protected to 680 protected areas in order to prevent vulnerable organisms from being killed (e.g. African 681 megafauna). In this scenario, protected areas are considered a sink, so the benefit is limited to 682 individuals that are more likely to survive under protection. However, following the IUCN 683 recommendations, conservation translocation must yield a measurable conservation benefit at 684 the level of the population, species or ecosystem. Protected areas thus need to shift their role 685 to become a source of translocated organisms and to provide long-distance benefits through 686 human assistance. Marine reserves host more abundant and larger individuals, thus producing 687 more larvae and juveniles than exploited areas $[6,19]$. The challenge is now to capture these 688 small larvae and juveniles, which are under high predation risk, to seed locally depleted or extinct populations elsewhere. This recently burgeoning strategy seems extremely promising.

690 For instance, Palau, a small island nation created one of the largest marine reserves on the 691 planet in 2015. Palau is now a sanctuary for marine animals that are globally endangered or 
692 under severe threats like the Bumphead Parrotfish (Bolbometopon muricatum) which has

693 critical and unique ecological functions in coral reef ecosystems [68]. The extremely high 694 density of Bumphead Parrotfish in Palau induces massive spawning aggregations from which 695 eggs can be collected and juveniles can be grown in tanks and then released at other sites 696 where this species has been depleted (Figure I). Humans protect individuals through the 697 period of high mortality and then release sub-adults in other reserves where populations have 698 been exploited or are still being exploited to restore a certain density. This example highlights 699 how marine reserves can play a pivotal role in long-distance translocations and broaden the 700 geographic extent of their benefits in the near future.

701

702

Figure I. The translocation process for the threatened Bumphead Parrotfish (Bolbometopon 703 muricatum) species from Palau. This island nation hosts the highest density of Bumphead

704 Parrotfish worldwide (A) due to severe fishing restrictions. Massive spawning aggregations 705 produce eggs (B) that can be caught without damage using nets (C). Larvae are then grown in 706 optimal conditions to avoid mortality and juveniles (D) can be released to restore depleted or 707 extinct local populations on overexploited reefs (E) but also revitalize a key functional role on 708 coral reefs by bio-eroding dead corals (F). Photos from Tom Bowling (Biota Palau).

709

710

711

712 
714 Admixture tracts: Continuous blocks of the genome inherited from an admixed population.

715 Benthic species: Species that live and feed in or on the seabed.

716

717 Blocks of identity by descent: Continuous blocks of the genome that share the same alleles 718 inherited from a common ancestor.

719

720 Cline analysis: A framework that uses the relation between the genetic variation and the 721 geography or environment to estimate dispersal and selection.

722

723 Coalescent theory: A model that traces back gene variants from populations to their common 724 ancestor.

Demersal species: Species that live and feed near the bottom of the sea floor.

727

Dispersal: In this context, any movement of individuals or propagules from a source location followed by successful immigration into a novel location with potential for gene flow.

Demographic connectivity: The process by which the dispersal of propagules, juveniles or adults affects population growth and vital rates.

733

734 Dispersal kernel: Probability function describing the distribution of dispersal distances. 
736 Genetic connectivity: A measure of gene flow and other evolutionary processes among

737 populations.

738

739 Gene flow: The exchange of genetic information among (sub)populations.

740

741

Haplotype: A combination of physically linked genetic variants on a single chromosome.

742

743

Isolation by distance: A pattern whereby genetic distance increases with geographic

744 distance. It can be used to estimate dispersal distance from population or individual genotype

745 data and regression analysis.

746

747 Larval dispersal: The dispersal of larvae from a spawning site to a settlement site.

748

749 Next-generation sequencing: Sequencing technologies that allows millions of DNA-

750 fragments to be sequenced in a single run.

751

752 Pelagic larvae: Larvae that spend time in the water column after hatching.

753

754 Pelagic species: Species living mainly in the water column.

755

756 Sessile species: Species that are fixed to a substratum for most of their life. Many sessile

757 species, however, have other stages in their life cycle, usually as eggs or larvae, that allow for 758 active or passive dispersal. 
760 Spillover: The net movement of (adult and juvenile) organisms across the boundary of a 761 reserve into a fished area.

Stepping-stone dispersal: A dispersal process involving intermediate steps across several generations.

Single nucleotide polymorphism markers: Molecular markers used to detect genetic variation among individuals that correspond to a difference in a single DNA building block, called a nucleotide.

769

770

771 Highlights and Outstanding questions inserted here for purposes of editorial markup.

\section{Highlights}

773

774

775

776

777
- Marine dispersal estimates are limited by the spatial scale of sampling design and therefore biased downwards;

- Active larval behavior, oceanographic eddies and fronts, tsunamis, marine debris and translocations are potentially important, but overlooked, dispersal vectors over long distances;

- The largest marine reserves have the highest potential for massive and long-distance benefits, but are the most isolated ones; 
- Long-distance dispersal has important consequences for the design of marine reserve networks;

Box 3: Outstanding questions Box

- What proportion of the dispersal kernel of marine species are we missing when we do not consider the long-distance $(>40 \mathrm{~km})$ dispersal?

- Is the restricted spatial scale of sampling designs the only or main cause of the limited geographical dispersal reported in the sea?

- What are the quantitative effects of marine reserves at long distances $(>40 \mathrm{~km}) ?$

- Is the unknown long-distance dispersal sufficient to connect large isolated marine reserves?

- To which extent future marine reserve networks should be composed of few but large reserves instead of many small when we consider species long-distance dispersal? 


\section{B All substrate-associated benthic and demersal marine species}
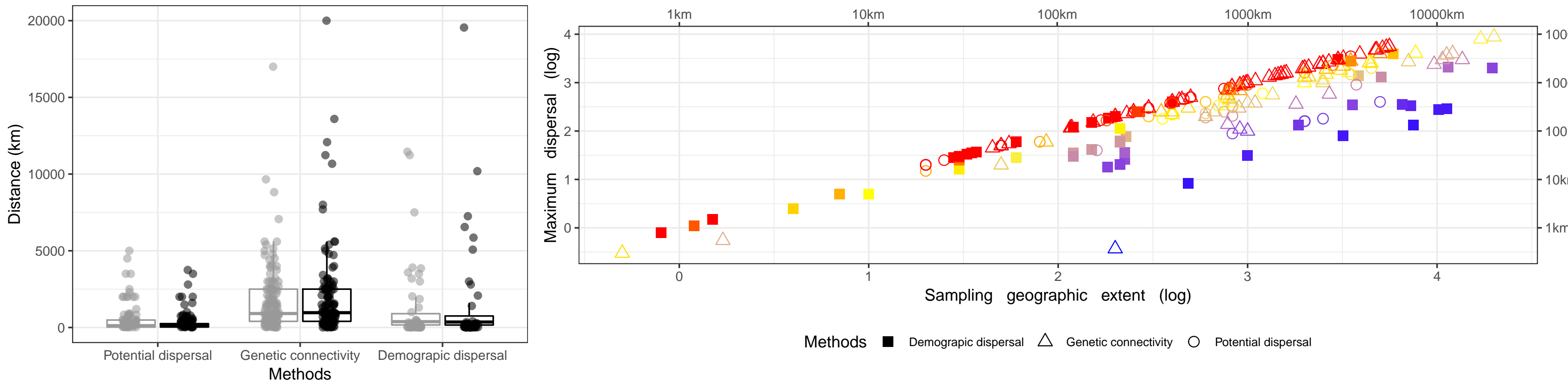

Methods $\square$ Demograpic dispersal $\triangle$ Genetic connectivity $\bigcirc$ Potential dispersal

宁 Sampling geographic extent Maximum dispersal

C Coastal fishes

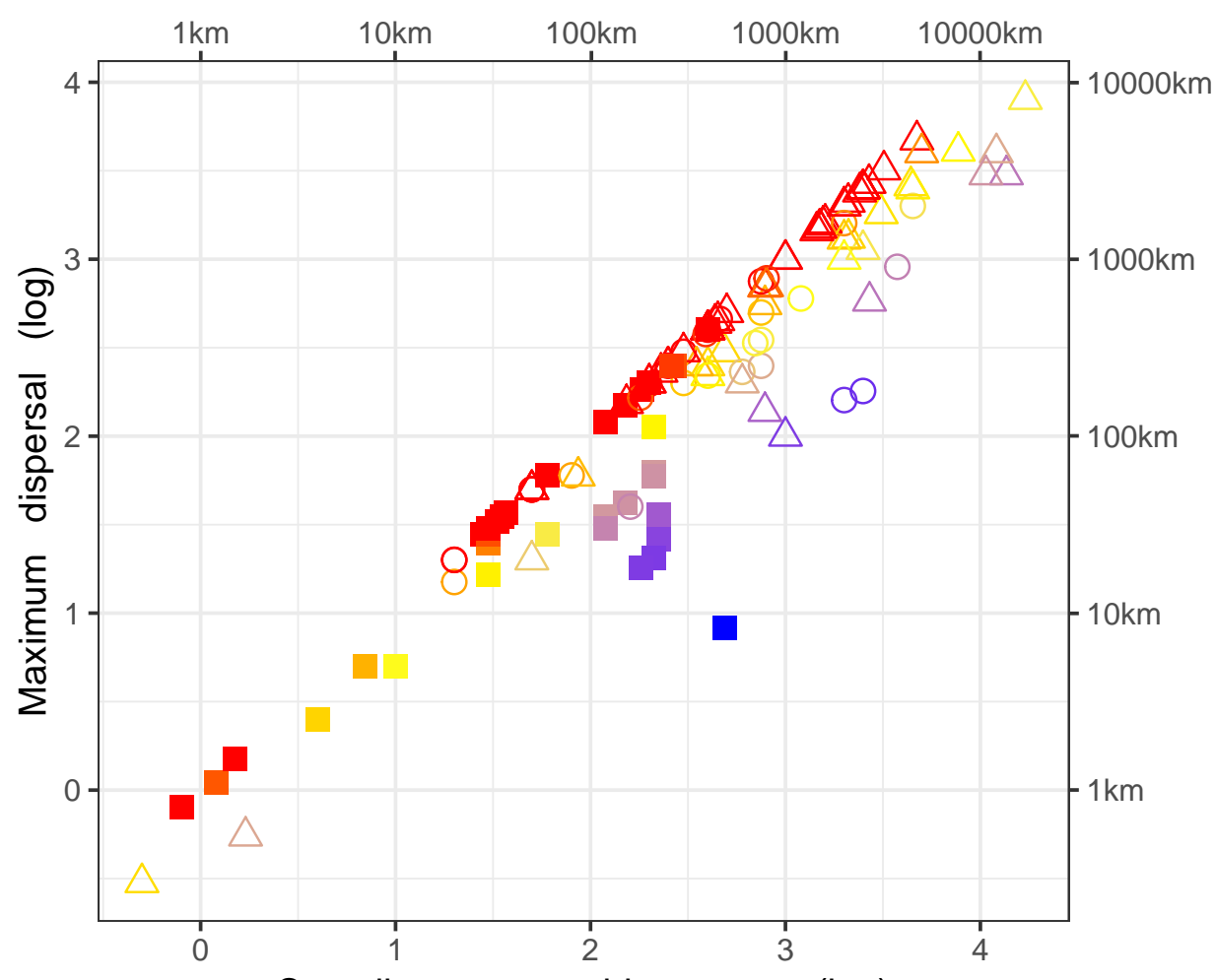

Sampling geographic extent (log)
Coastal invertebrates

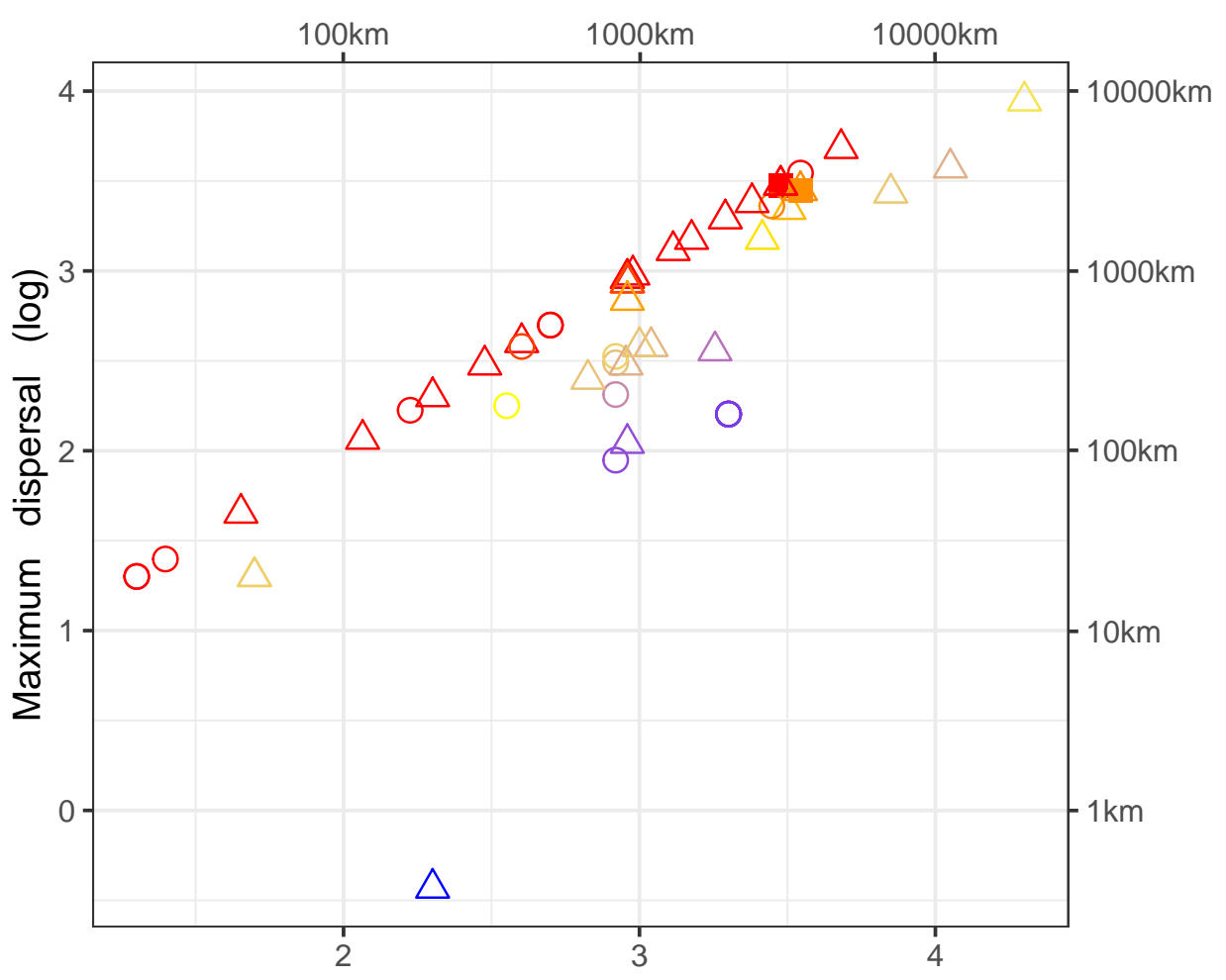

Sampling geographic extent (log)

\section{Difference $\begin{array}{llll}1 & 1 & & 1\end{array}$}

\section{Deep-sea macro-organisms}

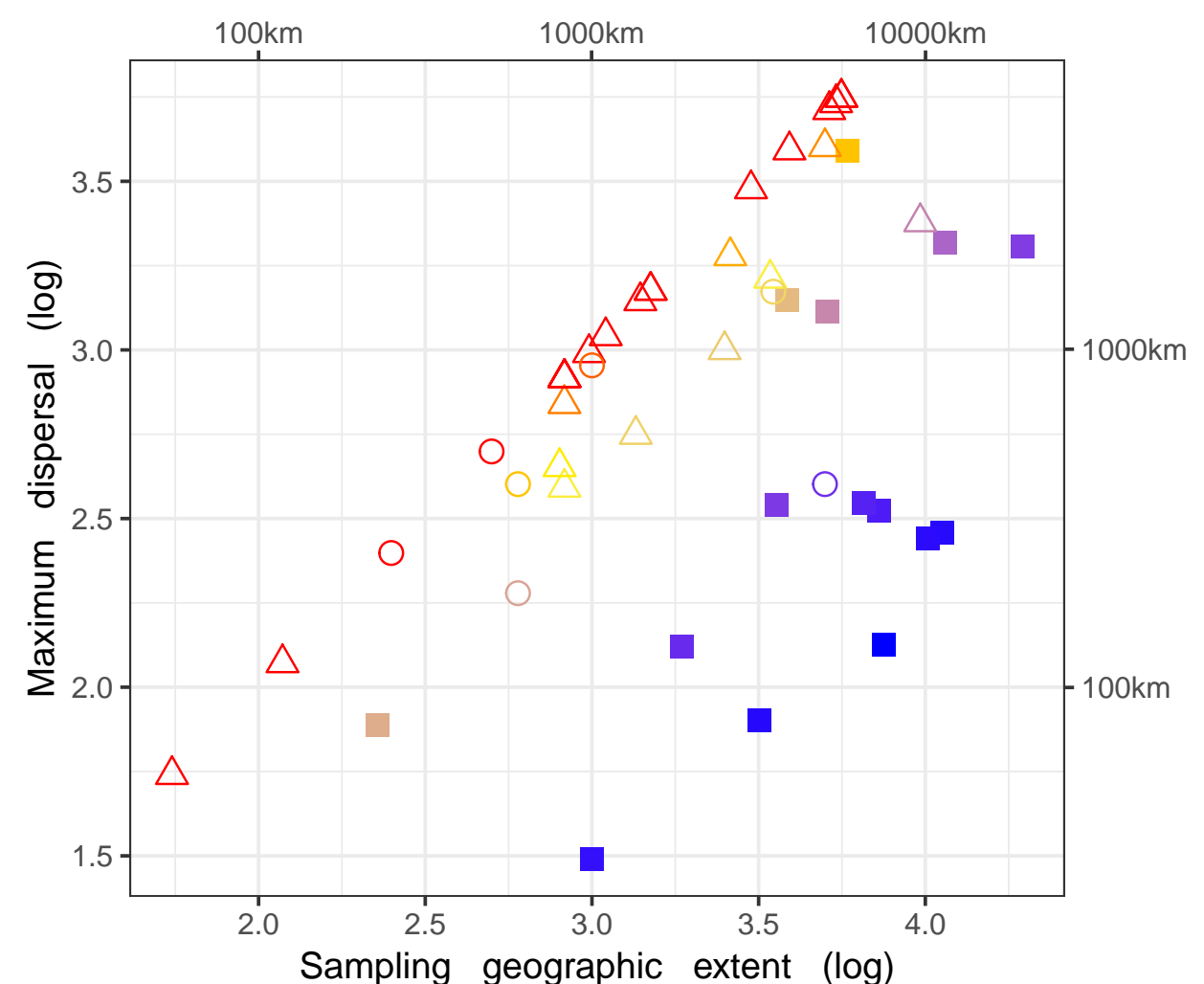




\section{PROCESSES}

1. Active dispersal

2. Passive dispersal by current

3. Drifting or floating debris

4. Translocation

\section{BENEFITS}

A. Increase of biomass (Fisheries)

B. Maintenance of biodiversity

C. Maintenance of cultural species

$\longrightarrow$ Marine Reserve

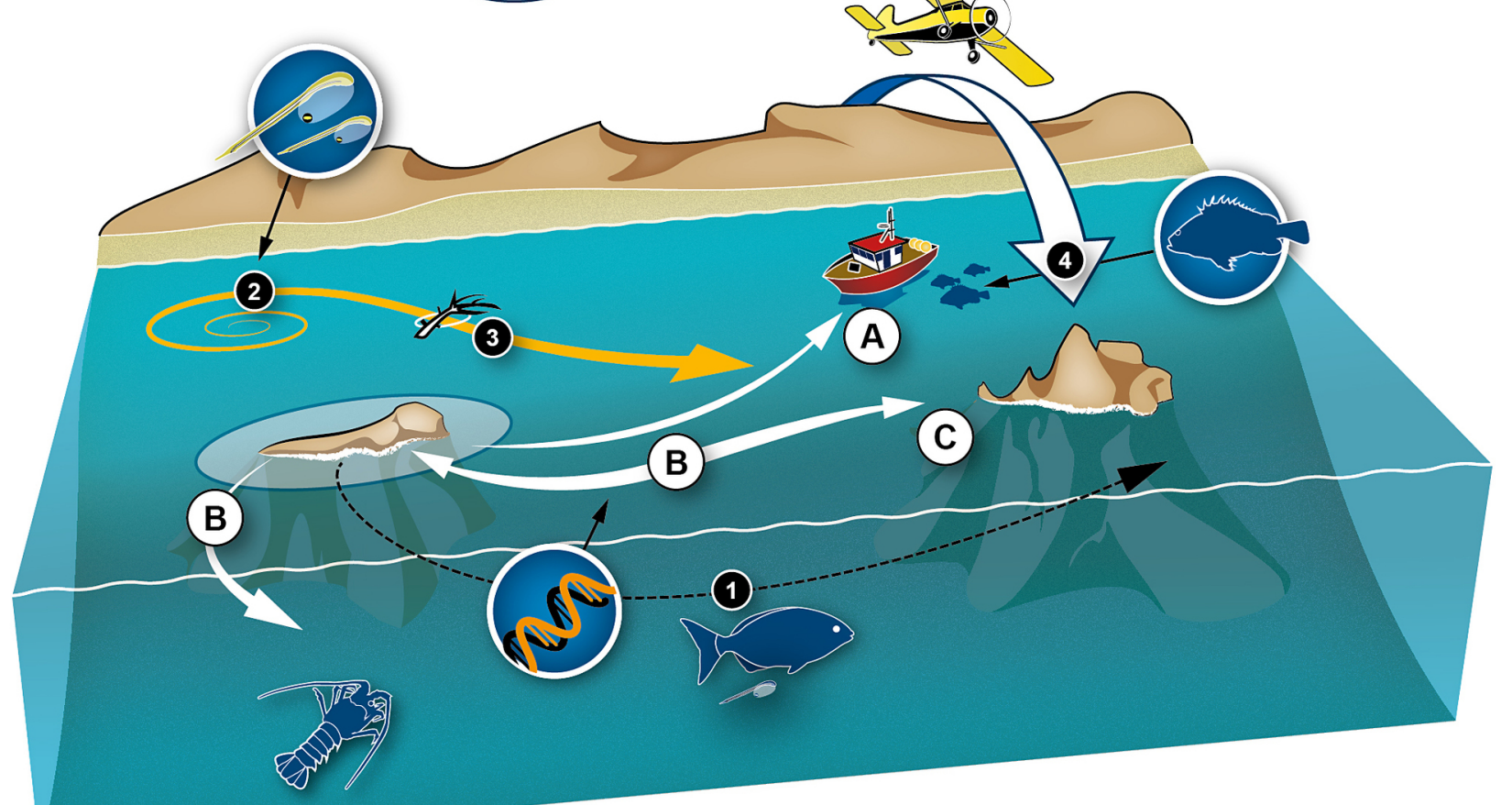


$\mathbf{A}$

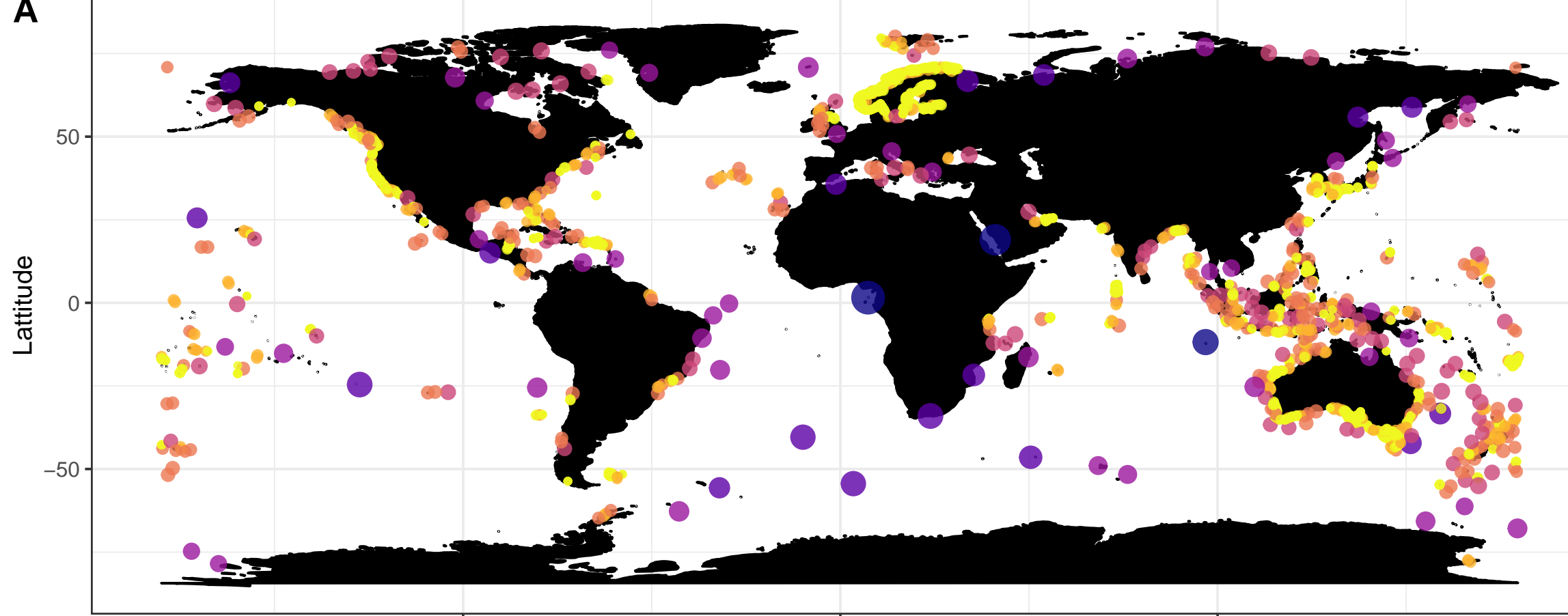

$-100$

Longitude

B

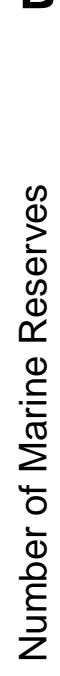

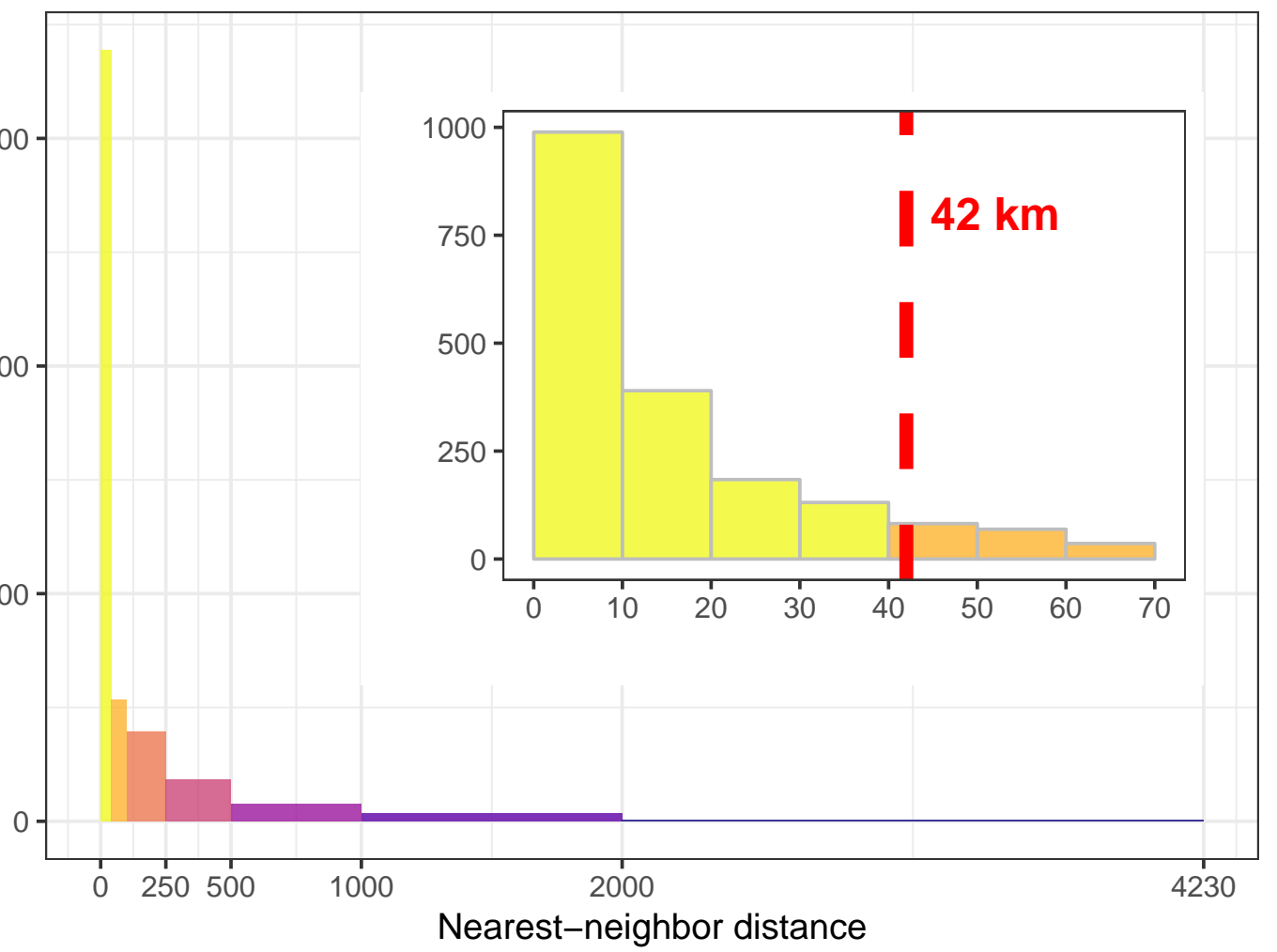

C

C $1 \mathrm{~km}^{2}$

$10000 \mathrm{~km}^{2}$

- $0-40 \mathrm{~km}$

- 40-100km

- $100-250 \mathrm{~km}$

- $250-500 \mathrm{~km}$

$500-1000 \mathrm{~km}$

$1000-2000 \mathrm{~km}$

2000-4230km

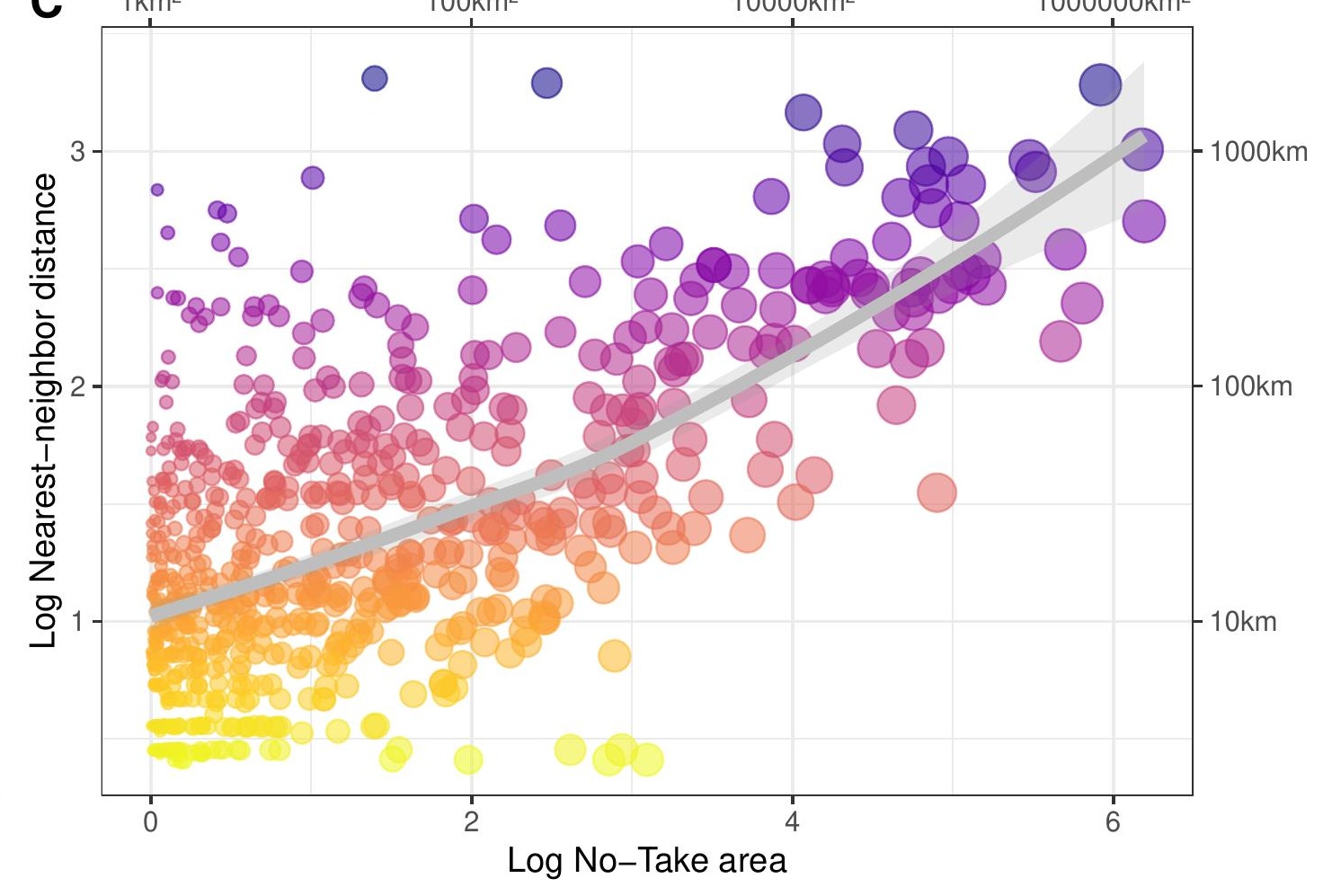

